\title{
PEMBUATAN EKSTRAK SEREH (Cymbopogon nardus L.) DALAM SEDIAAN LOTIO
}

\author{
Nurjannah Bachri, Nursalma, Natalia Nora \\ Sekolah Tinggi Ilmu Kesehatan Mega Rezky Makassar \\ Email : netcappucino@yahoo.co.id
}

\begin{abstract}
This experiment research have been conducted in the pharmaceutical technology laboratory, it aims of making the pharmaceutical in the form of latio of citronella extracts. This research used citronella as samples that are created macerationally and produced a thick extract. The making of lotio used smelting method, namely oil phase smelting and water phase smelting. It was done by observation in organoleptic to see the stability of lotio. Based on the observations result obtained that extracts of (Cymbopogon nardus L.) can be formulated in the latio and physically stable.
\end{abstract}

Key words : Citronella extracts, latio.

\section{PENDAHULUAN}

Indonesia sebagai negara tropis memiliki keanekaragaman sumber daya alam hayati. Keanekaragaman ini sangat bermanfaat, terutama dengan banyaknya spesies tumbuhan dan tanaman yang dapat digunakan sebagai obat. Tumbuhan dan tanaman obat ini telah dijadikan obat tradisional yang turun temurun karena obat tradisional memiliki banyak kelebihan diantaranya mudah diperoleh, harganya yang lebih murah, dapat diramu sendiri dan memiliki efek samping yang lebih kecil dibandingkan obat-obatan dari produk farmasi. Oleh sebab itu, kecenderungan masyarakat untuk menggunakan obat tradisional yang berasal dari alam atau herbal dalam pemeliharaan kesehatan.

$$
\text { Salah satu penggunaan }
$$
tanaman yang mampu menjadi insektisida nabati, salah satunya Sereh (Cymbopogon sp). Sereh memiliki spesies yang berbeda yaitu, sereh dapur (lemorgans) dan sereh wangi (citronella) keduanya memiliki aroma yang berbeda (Ambarwati, 2011).

Penelitian sebelumnya
menggunakan tumbuhan sereh
dilakukan oleh Kardinan dan Dhalimi,
2010 dari hasil penelitian diketahui
bahwa lotio minyak adas (Oleum


foeniculi) pada konsentrasi $5 \%$ dan $10 \%$ dalam air dapat bersifat repellent selama 2 jam pemakaian. Minyak sereh secara tradisional digunakan sebagai repellent nyamuk, fumigant (racun inhalasi) dipemukiman ataupun bahan pewangi pada makanan dan kosmetik (Nakahara et al., 2003).

Konsentrasi minyak sereh yang umum digunakan dalam produksi penolak serangga berkisar antara $0,05 \%$ hingga $15 \%$ baik secara tunggal maupun dikombinasikan dengan minyak lavender, cengkeh, ataupun minyak adas (Barnard, 2000). Berdasarkan hal tersebut, maka perlu dilakukan inovasi/pengembangan dalam memanfaatkan tanaman sebagai repellent ekstrak sereh (Cymbopogon nardus L.) dengan membuat dalam bentuk sediaan farmasi sebagai lotio ekstrak sereh.

\section{METODE PENELITIAN}

\section{Alat dan bahan yang digunakan}

Alat yang digunakan yaitu : seperangkat alat maserasi, vakum deksikator, alat-alat gelas (Pyrexgermany), neraca analitik, $\mathrm{pH}$ meter, viscometer, cawan porselin, dan kain kasa, oven.

Bahan yang digunakan yaitu : sereh (Cymbopogon nardus L.), etanol, asam asetat, sitosterol, trietanolamin, gliserin, BHA, asam benzoate, propel paraben, ol rosae, aquades, dan kertas saring.

\section{Prosedur kerja}

Pengambilan dan pengolahan sampel

Sampel yang digunakan pada penelitian ini tipe sereh wangi (Cymbopogon nardus L.) diambil di BTN Tritura, Kecamatan Manggala, Kota Makassar yang ditanam secara budidaya, akar dipisahkan dari bagian batang yang merupakan batang semu dan daun selanjutnya dicuci dengan air bersih, selanjutnya dipotong kecilkecil lalu dikeringkan dengan cara diangin-anginkan. Setelah kering, kurang lebih mengandung kadar air $\pm 10 \%$, sampel diserbukan dan siap digunakan sebagai bahan penelitian.

\section{Pembuatan Ekstrak}

Sampel sebanyak $500 \mathrm{~g}$ dimasukan kedalam wadah maserasi kemudian ditambahkan dengan 3 (tiga) liter pelarut $70 \%$ dan dibiarkan selama 24 jam sambil sekali-kali diaduk. Filtrat disaring dan ampas direndam lagi dengan pelarut yang sama. Hal ini dilakukan sebanyak $3 \mathrm{x}$ 24 jam. Filtrat dikumpulkan dan diuapkan pada rotavapor hingga diperoleh ekstrak etanol 70\% kental.

Ekstrak yang diperoleh ditimbang beratnya. Ekstrak sereh (Cymbopogon Nardus L.) yang telah 
didapatkan

pengujian/analisa

dianjurkan

pendahuluan,

kandungan air, kadar abu untuk menentukan komponen kandungan kimianya.

Uji komponen dilakukan untuk mengetahui adanya kandungan minyak atsiri, alkaloid, flavonoid, steroid atau terpenoid. Uji kualitatif dilakukan untuk mengamati warna ekstrak, bau (organoleptis) dan kekentalan ekstrak.

\section{Formulasi Lotio Ekstrak Sereh}

Prinsip formulasi lotio adalah pencampuran beberapa bahan disertai pengadukan dan pemanasan yang sempurna. Pembuatan lotio ekstrak sereh dibuat dengan 2 bagian yaitu fase minyak dan fase air. Fase minyak dilebur pada suhu $70^{\circ} \mathrm{C}$ membentuk adonan A, Fase air dicampur disertai dengan pemanasan $70^{\circ} \mathrm{C}$ sampai terbentuk adonan B. Campuran adonan A dituang pada adonan B hingga diaduk sampai haomogen, pencampuran dilakukan pada suhu $70^{\circ} \mathrm{C}$ lalu ditambahkan ekstrak sereh.

Formula lotio ekstrak sereh (Cymbopogon nardus L.) terdiri dari konsentrasi ekstrak yaitu $10 \%$. Lotio dasar (Lotion base) berdasarkan Jantan dan Zaki (1998) terdiri dari cetil alcohol, asam asetat, TEA, natrium laurel sulfat, gliserin, asam benzoat, propel paraben, BHA, dan aquadest.

Tabel 1. Formola lotio dasar ( Lotio base ) dan Lotio ekstrak

\begin{tabular}{clcc}
\hline \multirow{2}{*}{ No } & \multicolumn{1}{c}{ Bahan } & \multicolumn{2}{c}{ Konsentrasi } \\
\cline { 2 - 4 } & LB & LE \\
\hline 1. & Cetil alcohol & 1 & 1 \\
2. & Asam asetat & 10 & 10 \\
3. & TEA & 3 & 3 \\
4. & Natrium laurel sulfat & 0,4 & 0,4 \\
5. & Gliserin & 7 & 7 \\
6. & Propel paraben & 0,03 & 0,03 \\
7. & BHA & 0,03 & 0,03 \\
8. & Ol. Rosae & $\mathrm{qS}$ & $\mathrm{qS}$ \\
9. & Aquades & 78,34 & 78,34 \\
10. & Ekstrak Sereh & - & $10 \%$ \\
\hline Keterangan : & \multicolumn{2}{c}{} \\
LB : Lotio dasar & \multicolumn{2}{c}{} \\
LE : Lotio ekstrak & \multicolumn{2}{c}{}
\end{tabular}

\section{Evaluasi}

\section{Uji kestabilan lotio}

Pengujian kestabilan lotio, dilakukan dengan peleburan suhu ekstrak yaitu suhu panas pada $35^{\circ} \mathrm{C}$ dan suhu dingin pada $2^{\circ} \mathrm{C}$ dan amati creaming, kejernihan, bau, warna. Pengamatan kestabilan dilakuakan selama 4 minggu setiap 1 minggu sekali (Wilkinson and Moore, 1982).

\section{Uji pH}

Pengukuran $\mathrm{pH}$ dari formula lotio yang telah dibuat menggunakan pH stick, pH stick dicelupkan ke dalam sediaan lotio. Setelah tercelup dengan sempurna, amati perubahan warna pada $\mathrm{pH}$ stick tersebut dan sesuaikan dengan warna standar pada alat. Pengukuran dilakukan pada hari ke- 1 , 7, 14 , 21, dan hari ke- 28 (Yuliani, 2005). 


\section{Uji Organoleptis}

\section{Pengamatan}

organoleptis

meliputi pengamatan perubahanperubahan bentuk, warna, dan bau yang terjadi pada tiap rentang waktu tertentu selama 28 hari. Pengamatan organoleptis dilakukan pada hari ke1,7,14, dan hari ke- 28 (Yuliani, 2005).

\section{HASIL PENELITIAN}

\section{Ekstrak Sereh}

Tabel 2. Hasil dari pengamatan organoleptis ekstrak sereh

\begin{tabular}{ccc}
\hline No & Parameter & Hasil pengamatan \\
\hline 1. & Warna & Hijau muda \\
2. & Bau & Khas sereh \\
3. & Konsistensi & Kental \\
4. & Rendemen & $22,68 \mathrm{~g} / 500 \mathrm{~g}$ \\
\hline
\end{tabular}

\section{Organoleptis Lotio}

Table 3. Pengamatan organoleptis lotio

\begin{tabular}{|c|c|c|}
\hline Formula & Parameter & $\begin{array}{c}\text { Hasil } \\
\text { pengamatan }\end{array}$ \\
\hline \multirow{3}{*}{$F_{1}$} & Bau & $\begin{array}{l}\text { Khas oleum } \\
\text { rosae }\end{array}$ \\
\hline & Warna & Putih Susuh \\
\hline & Tekstur & $\begin{array}{c}\text { Halus, Tersebar } \\
\text { merata }\end{array}$ \\
\hline \multirow{3}{*}{$\mathrm{F}_{2}$} & Bau & $\begin{array}{l}\text { Khas minyak } \\
\text { atsiri sereh }\end{array}$ \\
\hline & Warna & Hijau Muda \\
\hline & Tekstur & $\begin{array}{l}\text { Halus, Tersebar } \\
\text { merata }\end{array}$ \\
\hline
\end{tabular}

Pengukuran pH dan Tipe Emulsi Lotio

Table 4. Pengukuran $\mathrm{pH}$

\begin{tabular}{cc}
\hline Formula & Hasil pengamatan \\
\hline $\mathrm{F}_{1}$ & 6,7 \\
$\mathrm{~F}_{2}$ & 6,3 \\
\hline
\end{tabular}

Table 5. Pengukuran Tipe Emulsi

\begin{tabular}{cc}
\hline Formula & Hasil pengamatan \\
$\mathrm{F}_{1}$ & $\mathrm{M} / \mathrm{A}$ \\
$\mathrm{F}_{2}$ & $\mathrm{~A} / \mathrm{M}$ \\
\hline
\end{tabular}

\section{PEMBAHASAN}

Bahan yang digunakan dalam penelitian ini adalah ekstrak sereh (Cymbopogon nardus L.) yang diketahui memiliki kandungan Terpenoid, alkaloid yang memiliki banyak manfaat dalam bidang kesehatan dan kosmetilk. Salah satu cara yang dilakukan untuk memperoleh ekstrak sereh adalah dengan cara ekstraksi.

Metode ekstraksi yang digunakan untuk ekstraksi sereh adalah metode maserasi dengan menggunakan cairan penyari $n$ Heksan dengan perbandingan $1: 2$. Metode ini lebih sederhana dan sangat menguntungkan dalam isolasi senyawa bahan alam karena dengan perendaman sampel tumbuhan akan terjadi pemecahan dinding dan membran sel akibat perbedaan tekanan antara didalam sel dan diluar sel, sehingga metabolit sekunder yang ada dalam sitoplasma akan terlarut dalam pelarut organic dan ekstraksi senyawa sempurna karena dapat diatur lama perendaman yang dilakukan. Keuntungan lain dari ekstraksi ini adalah peralatan yang 
digunakan sederhana dan mudah diusahakan.

Hasil ekstraksi sereh (Cymbopogon nardus L.) dengan menggunakan cairan penyari $\mathrm{n}$ Heksan diperoleh rendemen sebesar 22,68 g per 500 g simplisia kering. Pemilihan N-Heksan sebagai cairan penyari dikarenakan, karena n-Heksan sebagai pelarut non polar yang mampu menarik komponen kimia steroid, alkaloid dan minyak atsiri, dengan baik seperti citronellol dan geraniol yang dapat digunakan sebagai insektisida nabati dan kosmetika.

Pembuatan ekstrak sereh dalam bentuk sediaan Lotio karena mengandung senyawa minyak atsiri citronellol yang memiliki kemampuan sebagai repellent. Sediaan Lotio ekstrak sereh dibuat menggunakan dua formula lotio. Pembuatan formula dibuat dengan bahan dasar dan lotio bahan dasar ekstrak.

Bahan dasar sediaan lotio yang dibuat berdasarkan rancangan formula ekstrak sereh dari hasil pembuatan bahan dasar Lotio tersebut memiliki warna yang berbeda, diperoleh Lotio pada basis dengan warna putih bersih, dan variasi konsentrasi dengan warna yang kehijauan, bau khas pada masing-masing konsetrasi.
Sediaan lotio yang diperoleh selanjutnya diamati stabilitas fisiknya secara organoleptis. Berdasarkan pengamatan fisik formula terlihat stabil pada kedua formula baik dari segi warna, bau tekstur dan $\mathrm{pH}$. Pengukuran $\mathrm{pH}$ dilakukan untuk mengetahui $\mathrm{pH}$ yang baik pada lotio. $\mathrm{pH}$ yang direkomendasikan pada sediaan kulit yaitu pada pH 5,5 - 8.0. $\mathrm{pH}$ tersebut sangat ideal bagi lotio.

Pada lotio dengan ekstrak sereh memiliki keunggulan baik dari segi harga, lotio anti nyamuk berbahan aktif Sereh dapat bersaing dengan lotio anti nyamuk berbahan aktif, karena bahan baku tidak perlu inpor atau dapat dipenuhi dalam negeri. Untuk itu perlu digali dan terus diteliti agar daya proteksi dengan bahan ini dapat disejajarkan dan bersaing dengan lotio anti nyamuk berbahan aktif sintetik. Salah satunya dengan meningkatkan daya proteksi dan efektivitas lotio antara lain dengan penambahan zat yang bersifat fixative. Untuk menahan aromanya agar efektifitasnya dapat bertahan lebih lama.

Konsentrasi minyak sereh yang umum digunakan dalam produksi penolak serangga berkisar antara $0,05 \%$ hingga $15 \%$ sangat efektif digunakan sebagai anti repellent 
selama 2 jam pemakaian. Dilihat dari daya proteksi, efektifitas lotion anti nyamuk berbahan aktif ekstrak sereh masih berada dibawah efektifitas lotion anti nyamuk yang saat ini beredar dipasaran. Namun demikian, walaupun kalah dalam efektifitas, lotio anti nyamuk dari bahan alami lebih unggul dalam keamanan dan kesehatan bagi pengguna. karena DEET yang selama ini menjadi bahan aktif utama semua produk lotio anti nyamuk yang beredar dipasaran bersifat racun dan membahayakan bagi pengguna, khususnya anak-anak apabila penggunaannya kurang tepat.

Untuk itu perlu digali dan terus diteliti agar daya proteksi dengan bahan ini dapat disejajarkan dan bersaing dengan lotio anti nyamuk berbahan aktif sintetik. Salah satunya dengan meningkatkan daya proteksi dan efektivitas lotio antara lain dengan penambahan zat yang bersifat fixative. Untuk menahan aromanya agar efektifitasnya dapat bertahan lebih lama.

\section{KESIMPULAN}

Berdasarkan hasil penelitian yang telah dilakukan, dapat disimpulkan bahwa :

Metode yang digunakan dalam pembuatan lotio adalah ekstrak sereh.
1. Dalam penelitian ini, bagaimana metode pembuatan lotio ekstrak sereh dapat memenuhi persyaratan dan menghasilkan mutu yang baik.

2. Dalam penelitian ini, bagaimana cara untuk membuat sediaan farmasi dalam sediaan lotio ekstrak sereh.

\section{DAFTAR PUSTAKA}

Ambarwati, R.A., 2011. Deteksi Adanya Pemalsuan Minyak Sereh dengan Menguji Putaran Optik Menggunakan Polarimeter Tipe ATAGO 2L. Fakultas Teknik. Universitas Diponegoro, Semarang.

Barnard. 2000. Repellents and toxicants for personal Protection. Florida : Global Collaboration For development of pesticides for public Health (GCDPP) WHO.

Kardinan, A., Dhalimi, A., 2010. Potensi Adas (Foeniculum vulgare) sebagai bahan aktif lotion anti nyamuk demam berdarah (Aedes Aegypti). Bul. Littro. 21(1) $61-68$.

Nakahara, K., Alzoreky, N., Yodhihashi, T., Nguyeng, H.T., 2003. Chemical Compositio and antifungal activity of essential oil from Cymbopogon nardus (Citronella grass). JARQ. 37 249-252.

Wilkinson, J.B., Moore, R.J., 1982. Harry's Cosmeticology. George Godwin, London.

Yuliani, S.H., 2005. Formulasi Gel repellent minyak Atsiri 
Pembuatan ekstrak sereh (Cymbopogon nardus L.) dalam sediaan lotio

\author{
Tanaman Akar Wangi \\ (Vetivera zizanoides (L) ) : \\ Optimasi Komposisi Carbopol \\ $3 \%$ b/v-propilenglikol. Majalah \\ Farmasi Indonesia.
}

